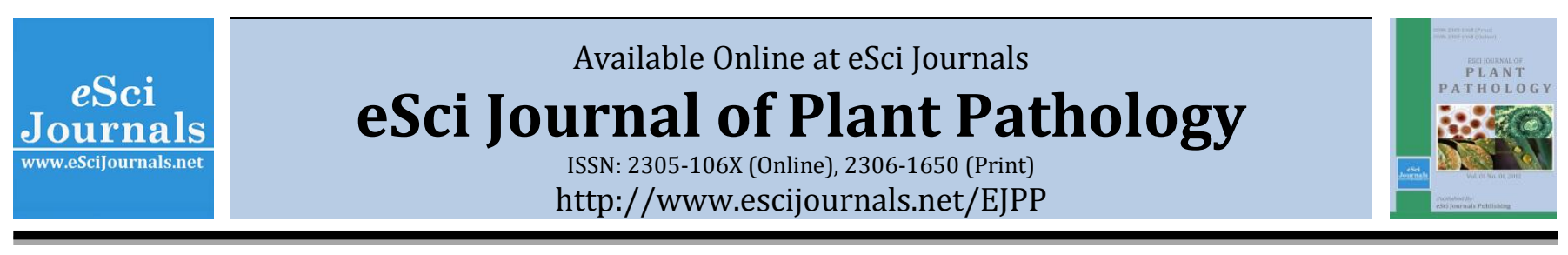

\title{
IMPACT OF CARBOHYDRATES AND MINERAL CONTENTS OF DIFFERENT INDIGENOUS STRAINS OF OYSTER MUSHROOM (Jacq.Fr.) CULTIVATED ON DIFFERENT AGRICULTURAL WASTES
}

\author{
Nasir A. Khan, Nazia Khaliq, Imran U. Haq, Nazir Javed, Amjad S. Gondal* \\ Department of Plant Pathology, University of Agriculture Faisalabad, Pakistan.
}

\begin{abstract}
A B S T R A C T
Different strains of Pleurotus ostreatus were cultivated on different agro-cellulosic wastes viz. cotton waste, wheat straw and paddy straw to determine the effect of these agro wastes on biological efficiency, carbohydrate and mineral contents including $\mathrm{Na}, \mathrm{K}, \mathrm{Ca}, \mathrm{Cu}, \mathrm{Zn}$ and Fe. Maximum biological efficiency was recorded on P. ostreatus (grey strain, $134.4 \%$ ) and (white strain, 113.7\%) on wheat straw. P. sajor-caju showed maximum biological efficiency (195.9\%) on wheat straw. Maximum amount of $\mathrm{Na}$ was found $(0.18 \mathrm{~g} / 100 \mathrm{~g}$ ) on P. ostreatus (grey strain) and $\mathrm{K}$ was found on $P$. sajor-caju (4.58g/100g) cultivated on paddy straw followed by wheat straw and cotton waste. P. ostreatus (white strain) cultivated on paddy straw showed maximum amount of $\mathrm{Cu}(0.0009 \mathrm{~g} / 100 \mathrm{~g})$ while maximum amount of $\mathrm{Zn}$ was found $(0.017 \mathrm{~g} / 100 \mathrm{~g}$ ) on P. ostreatus (white strain). Maximum amount of Fe was found (0.008g/100g) on P. sajor-caju cultivated on cotton waste. P. sajor-caju cultivated on cotton waste showed significantly highest carbohydrate $(0.079 \mathrm{~g} / 100 \mathrm{~g})$.
\end{abstract}

Keywords: Oyster mushroom, Pleurotus ostreatus, P. sajor-caju, mineral contents.

\section{INTRODUCTION}

Pleurotus species (Jacq.Fr) are widely cultivated throughout the world especially in Asia and Europe because of their low cost and simple production technology. They have high production and biological efficiency (Mane et al., 2007).Pleurotus species are rich in carbohydrate minerals (high in $\mathrm{P}, \mathrm{K}, \mathrm{Ca}, \mathrm{Fe}$, folic acid and low in $\mathrm{Na}$ ), fibers and contents as compared to other foods. They are also a rich source of essential and nonessential amino acids such as lysine which is low in cereals (Ali et al., 2007; Caglarirmak, 2007). Pleurotus specie has also very strong medicinal value especially in healing of three man killing diseases like cancer, heart disease and AIDS. Clinically these mushrooms have been used for treatment of fatigue, coughing, asthma, indigestion, neurosis, viral diseases, HIV, gout, tuberculosis, jaundice and antitumor. Pleurotus species is also an important diet for the patients of hypertension because they have high $\mathrm{Na}$ to $\mathrm{P}$ ratio (Agrahar-Murugkar

* Corresponding Author:

Email: amjadshahzad@live.com

(C) 2012 eSci Journals Publishing. All rights reserved.
\& Subbulakshmi, 2005; Danny et al., 2004).Pleurotus species have ability to grow efficiently in a variable range of temperature conditions $\left(15-30^{\circ} \mathrm{C}\right)$, so they can ideally be cultivated throughout the whole year in different agro-ecological zones in tropical countries including Pakistan. Due to increased nutritive value and low cost of production Pleurotus species have gain importance throughout the world as an extra agribussiness. These species have gained status followed by Agaricus bisporus especially P. ostreatus and P. sajorcaju. (Khan, 2009). Owing to efficient lignin degraders, Pleurotus species can be grown on different agrocellulosic wastes (Jandaik \& Goyal, 1995). Nutritional status of Pleurotus sajor-caju resembles very much with Pleurotus osteratus, except the fact that it has higher carbohydrate contents and more essential amino acids (Sangitrao, 2000). The present study was aimed to access the carbohydrates and minerals analysis of Pleurotus ostreatus (white \& gray strain) and Pleurotus sajor-caju with various agro-cellulosic wastes including cotton waste, wheat straw and paddy straw. Moreover the biological and production efficiency of three 
substrates in relation to nutrient enrichment and yield improvement was also compared.

\section{MATERIALS AND METHODS}

Substrate Preparation: Substrates viz. cotton waste, paddy straw and wheat straw were collected from agricultural farm and wetted thoroughly followed by stacking on the floor. Lime was used to adjust the $\mathrm{pH}$ of the substrates. Three Oyster spp. P. ostreatus (white strain), P. ostreatus (grey strain) and P. sajor-caju were used for effective cultivation.

Sterilization: Bags containing fermented substrates were sterilized in a 220 liter drum at $70^{\circ} \mathrm{C}$ for one hour. Heating and maintenance of temperature was carried out by providing continuous flame using commercial gas burner.

Spawning of bags: Prepared spawn of three oyster mushroom strains i.e. P. ostreatus (grey strain, white strain) and P. sajor-caju were obtained from Mushroom Laboratory, Department of Plant Pathology, University of Agriculture, Faisalabad. Spawning was done by inoculating the bags with $5 \mathrm{~g}$ of pure spawn. These bags were incubated for spawn running under complete darkness at room temperature. Data was recorded on $100 \%$ (full growth) of spawn completion in days of substrate bags.

Humidity \& Temperature: The bags were kept in the growing room where the humidity and temperature were maintained around $25^{\circ} \mathrm{C}$ and $80-90 \%$ respectively. Moisture requirements of the bags were accomplished by sprinkling water on them thrice a day using sprinkler. Humidifier was used to control the temperature of the growth room.

Ventilation: Sufficient light and ventilation was maintained for 20 days. Exhaust fan, operated 3-4 times was used for air flush to retain oxygen requirements during mushroom fructification.

Harvesting: Polythene bags were tear-off following the spawn run. Mycelial growth was recorded on all three substrates i.e. cotton waste, wheat straw and paddy straw. Formation of fruit bodies was evident within 3-4 days after removal of polythene bags. The beds were maintained up to the harvest of the third flush, completed in 35 days after spawning. A small layer of substrate was scrapped off from all the side of the beds after each harvest.

Yield and biological efficiency: In order to calculate biological and production efficiency of strains, the water contents of substrates at inoculation and at the end of incubation were measured. Biological and production efficiency was calculated by following formulas.

$$
\text { B.E }(\%)=\frac{\text { Fresh weight of mushroom harvested }}{\text { Substrate dry content before inoculation }} \times 100
$$

Production efficiency: Production efficiency of different strains was calculated by the following formula:

$$
\text { P.E }(\%)=\frac{\text { Fresh weight of mushroom harvested }}{\text { Substrate dry matter contents before croping }} \times 100
$$

Determination of mineral contents: The mineral contents including $\mathrm{Na}, \mathrm{K}, \mathrm{Ca}, \mathrm{Fe}, \mathrm{Cu}$ and $\mathrm{Zn}$ in all three oyster mushrooms cultivated on different substrates were determined using Atomic Absorption Spectrophotometer using wet digestion. One gram of sample was digested with $10 \mathrm{ml}$ of nitric acid: perchloric acid (7:3) mixtures at temperature up to $180-200^{\circ} \mathrm{C}$ till transparent contents was obtained. The contents were diluted to a volume of $100 \mathrm{ml}$ with double distilled water. Concentration of mineral contents was be determined by running the diluted samples through Atomic Absorption Spectrophotometry using air acetylene flame.

Determination of Carbohydrate contents: The carbohydrate contents of all three mushroom species cultivated on different substrates were determined by High Performance Liquid Chromatography (HPLC) method determined by AOAC (1990).

\section{RESULTS AND DISCUSSION:}

\section{Average yield of all flushes:}

Data recorded on average yield of all flushes of three mushroom species cultivated on different agro cellulosic wastes including cotton waste, paddy straw and wheat straw revealed that the maximum average yield of all flushes were taken by P. Sajor-caju (35.2gm) on wheat straw while minimum no. of days for average yield of all flushes were recorded (16gm) in wheat straw. P. ostreatus (white strain) showed maximum average yield of all flushes in (20.4 gm) on wheat straw While, P. ostreatus (gray strain) showed maximum average yield of all flushes in (24.26 gm) on Cotton waste and wheat straw as well. P. ostreatus (white and gray stains) give minimum yield on paddy straw. The overall performance of $P$. Ostreatus (gray strain) was the best on all three substrates in this. The best result found in reference to average yield was found in P. sajor- 
caju cultivated on wheat straw. The results were found in lined with Ali et al.,2007;Dundar et al.,2008 and Fanadzoet al., 2010.

Biological efficiency: Biological efficiency of mushrooms gives a best response estimate of economic importance output. Maximum biological efficiency (B.E) was noted on P. sajor-caju (195.9\%) on wheat straw while minimum biological efficiency (B.E) was recorded (97.7\%) on cotton waste. P ostreatus (white strain) showed maximum biological efficiency (113.7) on wheat straw. Biological efficiency on P. ostreatus on paddy straw (128.3) was more than on cotton waste (121.3). P. ostreatus (gray strain) showed maximum biological efficiency (134.4\%) on wheat straw and minimum $(121.3 \%)$ on cotton waste. Same results on biological efficiency of different strains of Oyster mushrooms were recorded by Omoangheet al., 2009; Sangitrao 2000 and Taniguchi et al., (2005).

Production efficiency: Maximum production efficiency was recorded with P. Sajor-caju (113.7\%) cultivated on wheat straw while minimum production efficiency was recorded $(80 \%)$ on cotton waste. $P$. ostreatus (white strain) showed maximum production

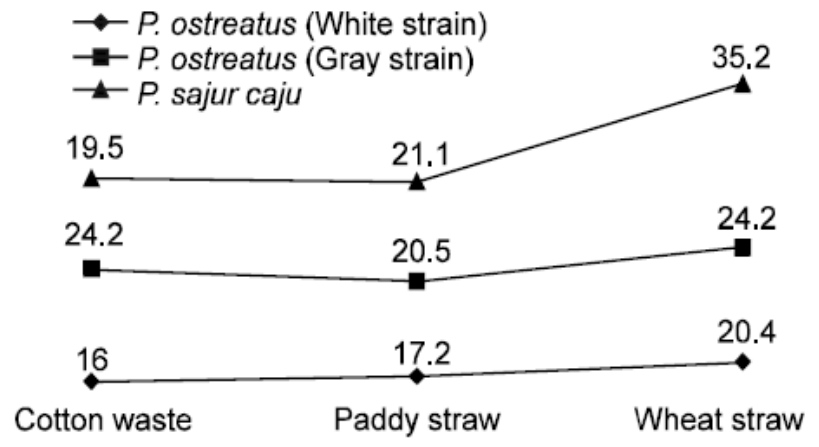

Fig. 1: Comparison of mean values of average yield of all flushes of different substrates.

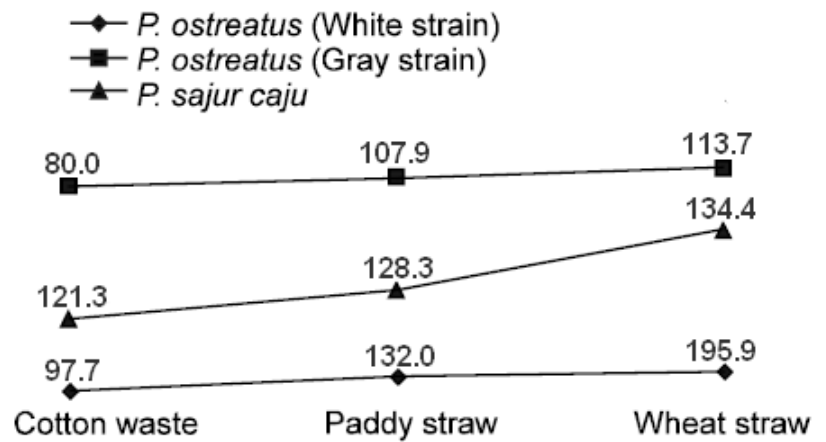

Fig. 3: Comparison of mean values of production efficiency of different substrates. efficiency $(113.7 \%)$ on wheat straw. P. ostreatus (grays strain) showed maximum production efficiency (134.8 and $134.4 \%$ ) on Cotton waste and wheat straw with a slight difference. The results were found in line with Kattan and Salama 1996; Pandey et al.,2008 and Saghiret al.,1998.

Estimation of amount of $\mathrm{Na}$ (g/100g): Regarding nutritional status of Oyster mushroom amount of different minerals is considered as the most significant. Sodium (Na) is one of the mineral that plays an important role in determination of mineral value and nutritional status of Oyster mushroom. Maximum amount of $\mathrm{Na}$ found of $(0.18 \mathrm{~g} / 100 \mathrm{~g})$ in P. ostreatus (gray strain) cultivated on paddy straw among all examined samples. While the minimum amount of $\mathrm{Na}(0.13)$ was found in P. ostreatus (white strain) cultivated on cotton waste. Similar minimum results were found in $P$. ostreatus (gray strain) P. ostreatus (white strain) and $P$. sajor-caju. Maximum amount of $\mathrm{Na}$ was found with all three mushroom species cultivated on paddy straw. The results found in this section are in line with Jafarpouret al., 2010; Dundaret al., 2009; Mattila et al., 2001 and Manzi et al., 1999.

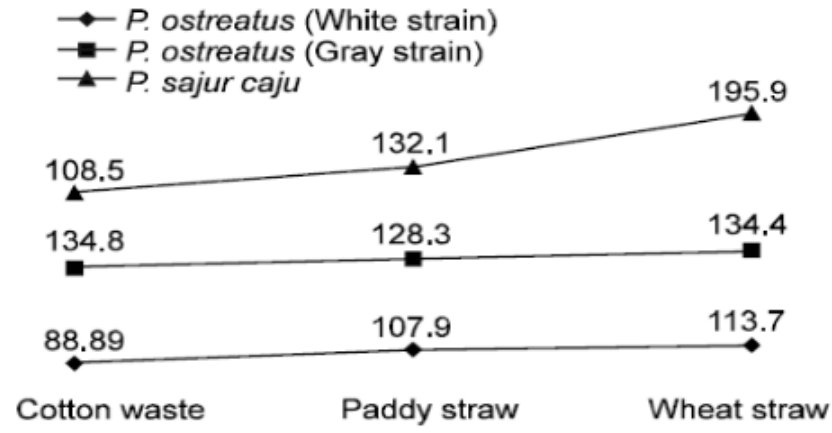

Fig. 2: Comparison of mean values of biological efficiency of different substrates.

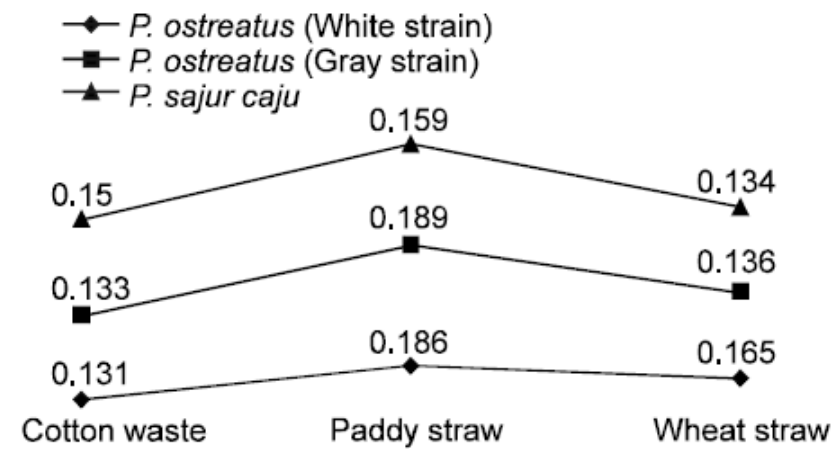

Fig. 4: Comparison of mean values of amount of sodium ( $\mathrm{Na})$. 


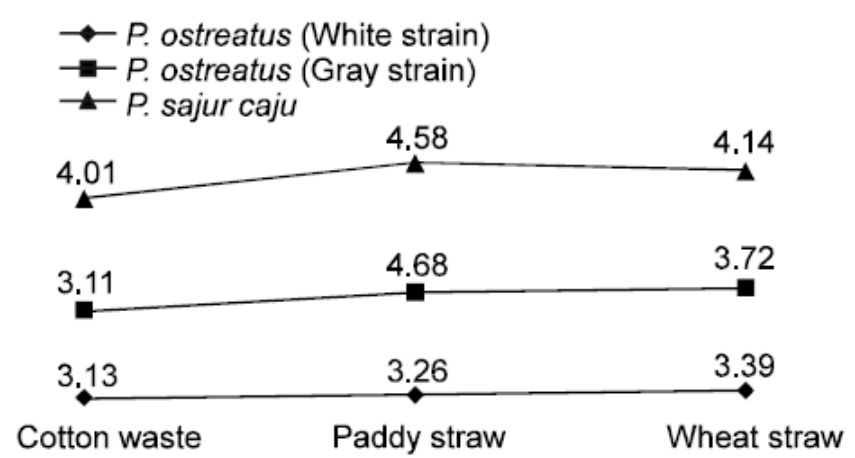

Fig. 5: Comparison of mean values of Potassium (K).

Estimation of amount of $K(\mathrm{~g} / \mathbf{1 0 0 g})$ : Maximum amount of Potassium (K) found of $(4.58 \mathrm{gm} / 100 \mathrm{gm})$ in $P$. sajor-caju cultivated on paddy straw while minimum amount of K (3.11gm/100gm) was found in P. ostreatus (gray strain) cultivated on cotton waste. Similar minimum results were found in $P$. ostreatus (gray strain) P. ostreatus (white strain) cultivated on three substrates. Maximum amount of $(\mathrm{K})$ was found in all mushroom species cultivated on paddy straw. The results found in this section are in line with Sangitrao2000; Zhang et al., 2002 and Sainoset al., 2006.

Estimation of amount of Ca (g/100gm): Calcium (Ca) is one of the minerals that play an important role in determination of mineral value and nutritional status of Oyster mushroom. The maximum amount of Ca found

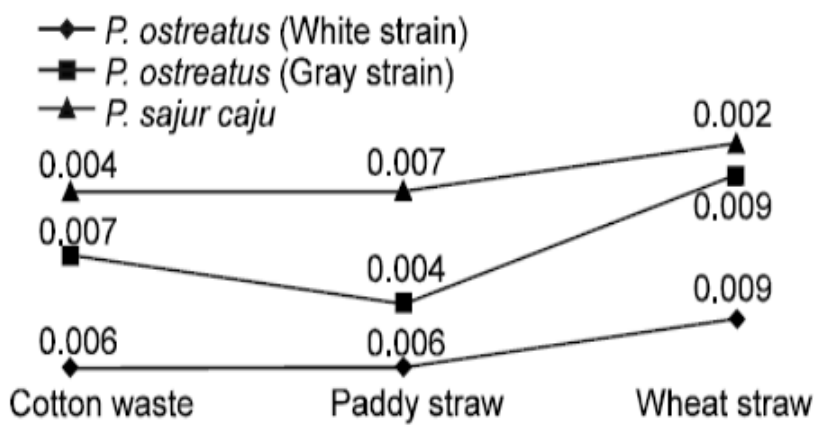

Fig. 7: Comparison of mean values of amount of Copper (Cu).

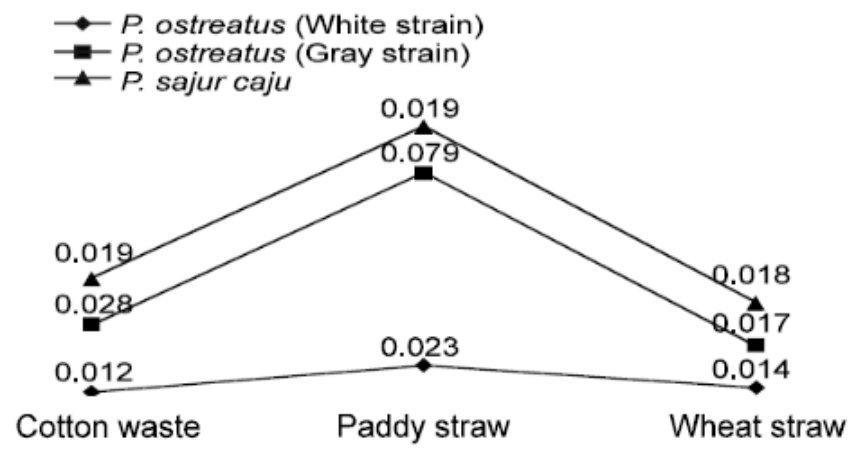

Fig. 9: Comparison of mean values of amount of Iron (Fe).

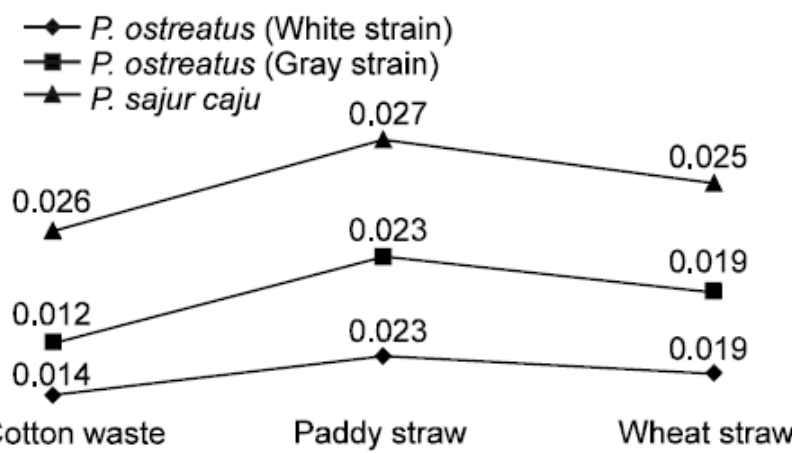

Fig. 6: Comparison of mean values of Calcium (Ca).

$(0.02 \mathrm{~g} / 100 \mathrm{gm})$ in P. sajor-caju cultivated on paddy straw among all examined samples. While the minimum amount of Ca $(0.012 \mathrm{~g} / 100 \mathrm{gm})$ was found with $P$. ostreatus (gray strain) cultivated on cotton waste. Maximum amount of Ca was found in three mushroom species cultivated on paddy straw. Similar results regarding the estimation of amount of $\mathrm{Ca}$ were recorded by Buyukalaca, 2010; Jafari et al., 2007 and Taniguchi et al., 2005.

Estimation of amount of $\mathbf{C u}(\mathrm{g} / \mathbf{1 0 0 g})$ : Maximum amount of $\mathrm{Cu}$ found of $(0.009 / 100 \mathrm{gm})$ in P. ostreatus (white strain) and P. ostreatus (grey strain) cultivated on paddy straw while the minimum amount of $\mathrm{Cu}$ $(0.002 \mathrm{~g} / 100 \mathrm{gm})$ was found in P. sajor-caju cultivated on wheat straw. Maximum amount of $\mathrm{Cu}$ was found in three mushroom species cultivated on wheat straw.

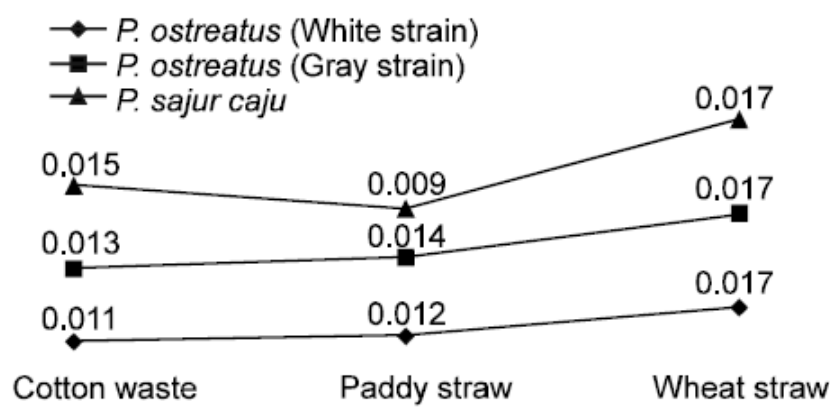

Fig. 8: Comparison of mean values of amount of Zinc (Zn).

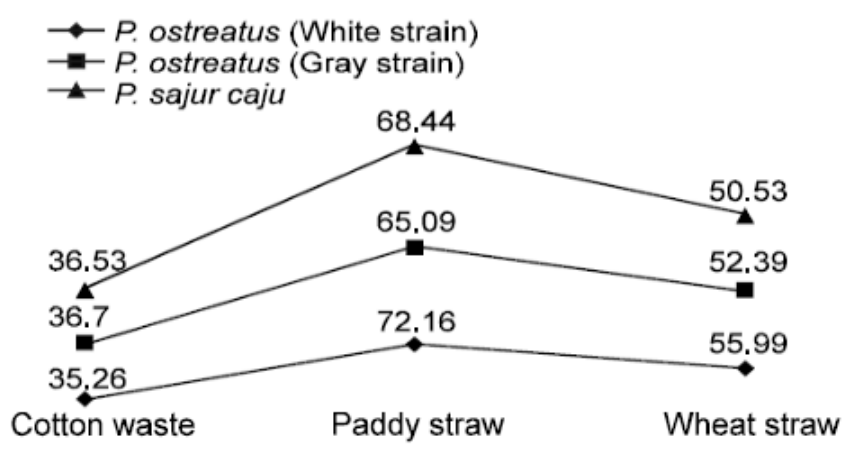

Fig. 10: Mean comparison values of amount of Carbohydrates. 
Results found in this section were found in line with Jafariet al., 2007; Vane et al., 2001 and Bisariaaet al., 2003. Maximum amount of $\mathrm{Zn}$ was found $(0.017 \mathrm{~g} / 100 \mathrm{~g})$ in all three mushroom species; P. sajorcaju, P. ostreatus (white strain) and P. ostreatus (grey strain) mushroom cultivated on wheat straw. While the minimum amount of $\mathrm{Zn}(0.009 \mathrm{~g} / 100 \mathrm{gm})$ was found in P. ostreatus (white strain) cultivated on cotton waste. Similar results regarding the estimation of $\mathrm{Cu}$ contents in different mushroom species cultivated of agro cellulosic wastes were recorded by Bisaria et al., 2003, Oyetayo, 2009 and Goyalet al., 2006.

Estimation of amount of $\mathrm{Fe}(\mathrm{g} / \mathbf{1 0 0 g})$ : Maximum amount of Fe found of $(0.008 / 100 \mathrm{gm})$ in P. sajor-caju cultivated on cotton waste among all examined samples. While the minimum amount of $\mathrm{Fe}$ $(0.079 \mathrm{~g} / 100 \mathrm{gm})$ was found in P. ostreatus (gray strain) cultivated on paddy straw. Amount of Fe recorded with P. ostreatus (white strain) cultivated on cotton was less $(0.012 \mathrm{~g} / 100 \mathrm{~g})$ that cultivated on paddy straw $(0.023 \mathrm{~g} / 100 \mathrm{~g})$ followed by cultivated on wheat straw $(0.014 \mathrm{~g} / 100 \mathrm{~g})$. Maximum amount of Fe was found in three mushroom species cultivated on paddy straw. The results found in this section were found in line with Oyetayo 2009; Carrera et al., 2000 and Bobek et al., 1996.

\section{Estimation of amount of Carbohydrates (g/100g):} Carbohydrates are the most important nutritional factor which is considered by most of nutritionists as well as nutrient conscious consumers. Maximum amount of Carbohydrates found of (55.99/100gm) in $P$. ostreatus (white strain) cultivated on wheat straw while the minimum amount of Carbohydrates (35.26g/100g) was found in P. ostreatus (white strain) cultivated on cotton waste. P. ostreatus (grey strain) give maximum amount carbohydrate $(65.09 \mathrm{~g} / 100 \mathrm{~g})$ followed by $(52.39 \mathrm{~g} / 100 \mathrm{~g})$ on paddy straw and $(37.60 \mathrm{~g} / 100 \mathrm{~g})$ on cotton waste. Maximum amount of Carbohydrates was found in all three mushroom cultivated on paddy straw. Similar results regarding estimation of amount carbohydrates were recorded by Bobeket al., 1996; Mandeel et al., 2005 and LeunMauet al., 1998.

\section{REFERENCES:}

Agrahar-Murugkar, D., G. Subbulakshmi. 2005. Nutritional value of edible wild mushrooms collected from the Khasi Hills of Meghalaya. J. Food Chem., 89, 599-603.
Ali, M.A., M.I. Mehmood, R. Nawaz, M.A. Hanif \& R. Wasim. 2007. Influence of substrate pasteurization methods on the yield of oyster mushroom (Pleurotus species). Pak. J. Agric. Sci. 44, 300-303.

Bisariaa, R., M. Madana, V.S. Bisariab \& S.N. Mukhopadhyay. 2003. Amino acid composition of the mushroom, Pleurotus sajor-caju, cultivated on different agroresidues. Biol. Wastes 20, 251-259.

Bobek, P., L. Ozdin \& L. Kuniak. 1996. Effect of oyster mushroom (Pleurotus ostreatus) and itsethanolic extract in diet on absorption and turnover of cholesterol in hypercholesterolemic rat. Nahrung 40, 222-224.

Buyukalaca, S. 2010. Yield performances and changes in enzyme activities of 465 Pleurotus spp. ( $P$. ostreatus and $P$. sajor-caju) cultivated on different agricultural 466 wastes. Bioresour. Technol. 101, 3164-3169.

Caglarirmak, N. 2007. The nutrients of exotic mushrooms (Lentinula edodes and Pleurotus species) and an estimated approach to the volatile compounds. Food Chem. 105, 11881194.

Dundar, A.R., H. Acay \& A. Yildiz. 2008. Yield performances and nutritional contents of three oyster mushroom species cultivated on wheat stalk. Afr. J. Biotechnol. 7, 3497-3501.

Fanadzo, M., D.T. Zireva, E. Dube \& A.B. Mashingaidze. 2010. Evaluation of various substrates and complements for biological efficiency of Pleurotus sajor-caju and Pleurotus ostreatus. Afr. J. Biotechnol. 9, 2756-2761.

Goyal, R., R.B. Grewal \& R.K. Goyal. 2006. Nutritional attributes of agaricus Bisporus and Pleurotus sajor-caju mushrooms. Nutr. Health 18, 179-184.

Jafari, M. A., A. Nikkhah, A.A. Sadeghi \& M. Chamani. 2007. The effect of Pleurotus spp. fungi on chemical composition and in vitro digestibility of rice straw. Pak. J. Biol. Sci. 10, 2460-2464.

Jafarpour, M., A.J. Zand, B. Dehdashtizadeh \& S. Eghbalsaied. 2010. Evaluation of agricultural wastes and food supplements usage on growth characteristics of Pleurotus ostreatus. Afr. J. Agric. Res. 5, 3291-3296.

Jandaik, C.L. \& Goyal, S.P. 1995. Farm and farming of oyster mushroom (Pleurotus sp). In:Mushroom Production Technology (Eds. Singh, R.P. and Chaube, H. S.). G. B. Pant Univ. Agri. Tech., Pantnagar India, pp. 72-78.

Kattan, R. and K. I. Salama. 1996. Evaluation of yield potential of two Pleutotus species. J. Ind. Microbiol. 34, 21-24.

Khan, N. A. 2009. Cultivation of Oyster mushroom on commoly available agricultural wastes in 
Pakistan .Ph.D thesis, Deptt.Pl. Pathol. Univ. Agri. Faisalabad, Pakistan.

LeunMau, J., Y. PinLin, P. TingChen, Y. HsinWu \& J. TorngPeng. 1998. Flavor compounds in king oyster mushrooms Pleurotus eryngii. J. Agric. Food Chem. 46, 4587-4591.

Mandeel, Q.A., A.A. Al-Laith \& S.A. Mohamed. 2005. Cultivation of oyster mushrooms (Pleurotus spp.) on various lignocellulosic wastes. World J. Microbiol. Biotechnol. 21, 601-607.

Mane, V., P. Patil, S.S. Syed \& M.M. V. Baig. 2007. Bioconversion of low quality lignocellulosic agricultural waste into edible protein by Pleurotus sajor-caju (Fr.) Singer. J Zhejiang Univ. Sci. 8, 45-50.

Manzi, P., L. Gambelli, S. Marconi, V. Vivanti \& L. Pizzoferrato. 1999. Nutrients in edible mushrooms: An inter-species comparative study. Food Chem. 65, 477-482.

Martinez-Carrera, D., A. Aguilar, W. Martínez, M. Bonilla, P. Morales \& M. Sobal. 2000. Commercial production and marketing of edible mushrooms cultivated on coffee pulp in Mexico. Chapter 45, pp. 471-488.

Mattila, P., K. Kanko, M. Earola, J.M. Pihlava, J. Astola \& L. Vahterist. 2001. Contents of vitamins, mineral elements, some phenolic compounds in cultivated mushrooms. J. Agric. Food Chem. 49, 2343-2348.

Omoanghe Isikhuemhen, S. \& A.N. Mikiashvilli. 2009. Lignocellulolytic enzyme activity, substrate utilization and mushroom yield by Pleurotus ostreatus cultivated on substrate containing anaerobic digester solids. J. Ind. Microbiol. Biotechnol. 36, 1353-1362.
Oyetayo, F.L. \& V.O. Oyetayo. 2009. Assessment of nutritional quality of wild and cultivated Pleurotus sajor-caju. J. Med. Food 12, 1149-1153.

Pandey, R.K., I.B. Pandey \& S. Jha. 2008. Performance of oyster mushroom (Plurotus sajor-caju) on different agricultural wastes. Agricultura, Agric. Practice Sci. J. Vol., 67.

Saghir, A.S., 1998. Studies on different strains of oyster mushroom (Pleurotus spp.) on cotton waste. M.Sc Thesis, Deptt. Pl. Pathol, Univ. Agri, Faisalabad.

Sainos, E., G. Diaz-Godínez, O. Loera, A.M. MontielGonzalez \& C. Sanchez. 2006. Growth of Pleurotus ostreatus on wheat straw and wheat grain-based media: Biochemical aspects and preparation of mushroom inoculum. Appl. Microbiol. Biotechnol. $72,812-815$.

Sangitrao, C.S. 2000. High production technology for Oyster mushroom Pleurotus sajor-caju (Fr.) Singer. Science and cultivation of edible fungi. Proceedings of the 15th International Congress on the Science and Cultivation of Edible Fungi, Maastricht, Netherlands. pp. 959-962.

Taniguchi, M., H. Suzuki, D. Watanabe, K. Sakai, K. Hoshino \& T. Tanaka. 2005. Evaluation of pretreatment with Pleurotus ostreatus for enzymatic hydrolysis of rice straw. J. Biosci. Bioeng. 100, 637- 643.

Vane, C.H., S.C. Martin, C.E. Snape \& G.D. Abbott. 2001. Degradation of lignin in wheat straw during growth of the oyster mushroom (Pleurotus ostreatus) using off-line thermochemolysis with tetramethylammonium hydroxide and solid-state (13)C NMR. J. Agric. Food Chem. 49, 2709-2716.

Zhang, R., X. Li \& J.G. Fadel. 2002. Oyster mushroom cultivation with rice and wheat straw. Bioresour. Technol. 82, 277-284. 